\title{
Needs assessment for cooperative extension dairy programs in California
}

\author{
J. P. N. Martins, ${ }^{1,2 *}$ B. M. Karle, ${ }^{3}$ and J. M. Heguy ${ }^{4}$ \\ ${ }^{1}$ Department of Medical Sciences, School of Veterinary Medicine, University of Wisconsin-Madison, Madison 53706 \\ ${ }^{2}$ University of California Agriculture and Natural Resources, Cooperative Extension, Tulare 93274 \\ ${ }^{3}$ University of California Agriculture and Natural Resources, Cooperative Extension, Modesto 95358 \\ ${ }^{4}$ University of California Agriculture and Natural Resources, Cooperative Extension, Orland 95963
}

\section{ABSTRACT}

The present study aimed to identify dairy producer needs and how best to direct and deliver cooperative extension (CE) programming. In March 2017, we mailed a needs assessment survey to grade A dairy producers in California $(\mathrm{n}=1,080)$. The response rate was $15.4 \%(\mathrm{n}=166)$ and herd size averaged 1,405 milking cows (range 83-5,500). The geographic distribution of survey responses was representative of the distribution of dairies throughout the state. Producers were asked to indicate the level of concern for a predetermined list of 11 issues. Rank of concern had 3 numeric levels: (1) very concerned, (2) somewhat concerned, or (3) not concerned. Mean and percentage of responses in each rank for each issue topic were calculated. The top 5 concerns/obstacles indicated were (1) milk price, (2) labor availability/quality, (3) environmental issues/ regulations, (4) labor costs, and (5) water quality/ availability. Surveyed respondents were also asked to determine the level of priority of a predetermined list of $13 \mathrm{CE}$ research and educational opportunities. Producers ranked topics as low, medium, or high priority. The 5 highest priority research topics were (1) herd health, (2) environmental issues, (3) reproduction, (4) milk quality, and (5) water quality. The 5 highest priority educational topics were (1) herd health, (2) milk quality, (3) reproduction, (4) environmental issues, and (5) calf and heifer management. Producers were then asked to identify the target audience for CE information delivery and preferred information delivery method. Most respondents indicated that the target audience should be dairy owners $(93 \%)$ or managers $(66 \%)$. Fewer producers indicated a target audience of dairy employees $(27 \%)$ or allied industry (23\%). Preferable information delivery methods were newsletter or magazine articles (81\%), half-day/short meetings $(47 \%)$, and on-farm training/meetings (39\%). Webinars and 2- or 3-d des-

Received November 7, 2018.

Accepted April 6, 2019.

*Corresponding author: jp.martins@wisc.edu tination meetings were the least preferable methods (27 and 9\%, respectively). Survey results will serve to develop future dairy cooperative extension programs in California.

Key words: dairy, needs assessment, cooperative extension

\section{INTRODUCTION}

The structure of the dairy industry has changed significantly over the years in the United States. The number of registered dairy herds has decreased and dairy herds have become larger. The California dairy industry structure has followed the same trend. In 2001, there were 2,157 dairies in California with an average of 721 cows per dairy (CDFA, 2003), compared with 1,331 dairies in 2017, with an average of 1,304 cows per dairy (CDFA, 2018b). With these changes, fewer individuals are directly involved with on-farm management, and dairy producer participation in cooperative extension (CE) dairy educational programs has decreased. Also, many commercial companies in the dairy sector have started to provide specialized consultant support to these large dairy operations as part of their routine customer service package. Dairy producers began to use allied industry consultants as a source of information for an "extension" type service (Russell and Bewley, 2011).

Furthermore, land-grant universities continue to struggle with financial pressures that have affected programming and staffing. The numbers of full-timeequivalent dairy extension specialists in several universities have decreased considerably during the last 2 decades (Hutjens and Baltz, 2000; Bernard, 2019). University of California CE staffing levels in the dairy programmatic area have also decreased significantly, from 8 county-based advisors in the state in 2001, to 4 in 2017. Since the number of county-based advisors decreased, the geographic area covered by each advisor increased. Cooperative extension advisors became responsible for two or more counties, providing a multicounty service. As previously anticipated by Chase et 
al. (2006), it became more important to determine the impact of the extension program to justify the program and obtain grants as the extension budget decreases.

The development of smartphones, new electronic technologies, and social media venues have increased the opportunity for extension professionals to reach their clientele. At the same time, these developments have increased the number of alternate sources of information available. Extension professionals need to assess the use of the internet and social media as a learning and educational tool. Therefore, it is vital to understand clientele interests and needs to improve existing programs and the use of the internet and social media to deliver this information.

Cooperative extension has been an essential part of California's dairy industry, serving as a source of unbiased science-based information for dairy producers. Resource limitations and a changing dairy industry motivated our effort to assess the priorities for $\mathrm{CE}$ dairy extension and research programs in the state of California. Therefore, the objective of this study was to identify dairy producer needs and how to best direct and deliver CE programming.

\section{MATERIALS AND METHODS}

A complete list of all grade A dairy producers in California with addresses $(\mathrm{n}=1,353)$ was obtained from the California Department of Food and Agriculture (CDFA) in January 2017. Duplicate owner addresses ( $\mathrm{n}=267)$ were removed from the list. In March 2017, producers $(\mathrm{n}=1,086)$ were mailed an invitation letter to participate in the study, a double-sided one-page survey with 14 questions, and a prepaid return envelope. The objective of the survey was to identify dairy producer needs and how to best direct and deliver University of California Cooperative Extension (UCCE) dairy programs. The invitation letter included the objectives of the survey, a statement of information confidentiality, and a link and a QR code with the option to complete the survey online. The invitation letter also stated that a $\$ 10$ gift card would be provided to the first 100 respondents. In April 2017, a survey reminder was posted in the California Dairy Newsletter (University of California Agricultural and Natural Resources, 2017) and sent to subscribers by email and mail. Survey responses were received until May 30, 2017.

Four surveys were returned as "not deliverable and unable to forward." Two respondents had recently sold their operations and did not complete the survey. Thus, the total number of mailings was 1,080. A total of 166 surveys were returned, resulting in a response rate of $15.4 \%$, which was similar to a previous survey sent by
UCCE (Heguy et al., 2016). A small number of respondents $(8 \% ; n=14)$ only answered the front page of the survey. Overall, the total survey error was $7.0 \%$ with a 95\% confidence level (Custom Insight Inc., 2010).

The survey focus was California dairy need areas (obstacles and education opportunities) and desired direction of further UCCE research. General information, for demographic purposes, was collected. The survey also asked respondents' job title (e.g., owner, manager), number of milking cows in the herd, the frequency of veterinary service (weekly, biweekly, monthly, not regularly, never, or on-farm veterinarian) and whether a nutrition consultant was used to balance rations (yes or no). Few respondents did not provide specific information regarding job title $(\mathrm{n}=6)$, number of milking cows $(n=2)$, veterinary frequency $(n=2)$, and use of a nutrition consultant $(\mathrm{n}=5)$. "No responses" were considered missing data and were excluded from the analysis of the particular question. One of the respondents also wrote "bimonthly," which was replaced with the option "not regularly." Producers indicated their level of concern $(1=$ very concerned, $2=$ somewhat concerned, or $3=$ not concerned) for 11 topics and ranked 13 potential UCCE research and educational topics as high, medium, or low priorities. Concern topics included milk price/pricing, feed costs/availability of feeds, labor availability/quality, labor cost, herd health issues, environmental concerns/regulations, water quality/availability, animal well-being, consumer demands, farm succession, and urban encroachment. The UCCE research and educational topics included herd health issues, reproduction, nutrition, silage management, milk quality, alternative feedstuffs, calf and heifer management, organic/pasture management, environmental issues, heat stress, irrigation management, manure management, and water quality. The survey also allowed producers to write in and rank "other" options of concern or UCCE research and educational topics. Respondents who did not respond to a specific research priority were included as "no response." Respondents who did not rank any of the UCCE research $(\mathrm{n}=14)$ or educational $(\mathrm{n}=17)$ topic questions were excluded from the analysis of the particular question. A couple of questions addressed the desired target audience (owner, manager, employees, and allied industry) and how UCCE should deliver information (newsletter/ magazine articles, webinars, half-day or shorter meetings, 2- or 3-d destination meetings, and on-farm training/meetings). Respondents who did not answer the questions related to delivery of information $(\mathrm{n}=14)$ or desired target audience(s) $(\mathrm{n}=16)$ were excluded from the analysis of each question. The final question was designated for producers who indicated that the 
University of California should deliver information to dairy employees on the previous question. Respondents could indicate the method and preferred language option (English, Spanish, or both) to deliver information to dairy employees.

Surveys were categorized by herd size $(\leq 500,501$ to $1,000,1,001$ to 2,000 , and $>2,000$ lactating dairy cows) and 3 distinct geographic regions within the state to gain additional insight into regional differences as described in Love et al. (2016). The regions evaluated were Northern California (NCA), northern San Joaquin Valley (NSJV), and greater Southern California (GSCA; Figure 1). Concern or priority level means among categories or regions were calculated using the PROC MEANS procedure of SAS 9.4 (SAS Institute Inc., Cary, NC). Mean response for concern or research and extension priority level of each topic was calculated after assigning a numeric value to respondents' concern level (very concerned $=1$, somewhat concerned $=2$, or not concerned $=3$ ) or priority level (high priority $=$ 1 , medium priority $=2$, or low priority $=3$ ). Concern or UCCE research and educational topics were ranked based on the means. The proportion of responses in each rank level or regional differences were calculated using PROC FREQ. Chi-squared test was used with the CHISQ option of PROC FREQ to test differences in proportions between regions or other categorical variables. Differences on continuous variables such as herd size and concern or priority level means were analyzed by least squares ANOVA, using the GLM procedure of SAS. Multiple comparisons differences were analyzed using Tukey's test. Statistical differences were considered significant at a 0.05 significance level.

\section{RESULTS AND DISCUSSION}

\section{General Information}

The majority of survey respondents (88\%) were dairy owners. Few owners (8\%) also indicated that they were responsible for the management of their dairy (owner/ manager). A small percentage of the surveys were completed by managers $(6.6 \%)$, herdsmen $(1.2 \%)$, and secretarial staff $(0.6 \%)$. Six respondents $(3.6 \%)$ did not indicate their job title. The results of this survey represent mainly the views of California dairy producers, which represents one of the groups of clientele that dairy extension programs target. In a recent survey conducted in California using a similar methodology, the majority of respondents $(78 \%)$ were also herd owners (Love et al., 2016). Surveys that target a different clientele group such as herd managers may need to use a different methodology such as personal or phone interviews.
The sum of lactating dairy cows for respondents was 230,474 milking cows, which was approximately $13.3 \%$ of the total number of milking cows in California in 2017 ( $\mathrm{n}=1,735,350$; CDFA, 2018b). The average herd size ( $\mathrm{n}$ $=164$ respondents) was 1,405 milking cows, which was comparable to the 2017 average herd size for California dairies (1,304 milking cows; CDFA, 2018b). A recent survey conducted in California (Love et al., 2016) had similar herd size averages. Average herd size was also comparable to 2017 average herd size of other states in the western United States, including Nevada (1,600 milking cows/dairy), Colorado (1,333 milking cows/ dairy), Texas (1,278 milking cows/dairy), and Idaho (1,176 milking cows/dairy; USDA, 2018). Producers in these states with similar herd sizes may be facing similar production problems as California dairy producers. Herd size of respondents' dairies in our study ranged from 83 to 5,500 milking cows, and the median was 1,150 milking cows. Of the total respondents, $25.6 \%$ had $\leq 500,21.3 \%$ had 501 to $1,000,28.7 \%$ had 1,001 to 2,000 , and $24.4 \%$ had $>2,000$ milking cows.

The geographic distribution of survey responses was representative of the distribution of dairies in the 3 dairy regions of the state (Figure 2$)$. Fewer $(P<0.01)$

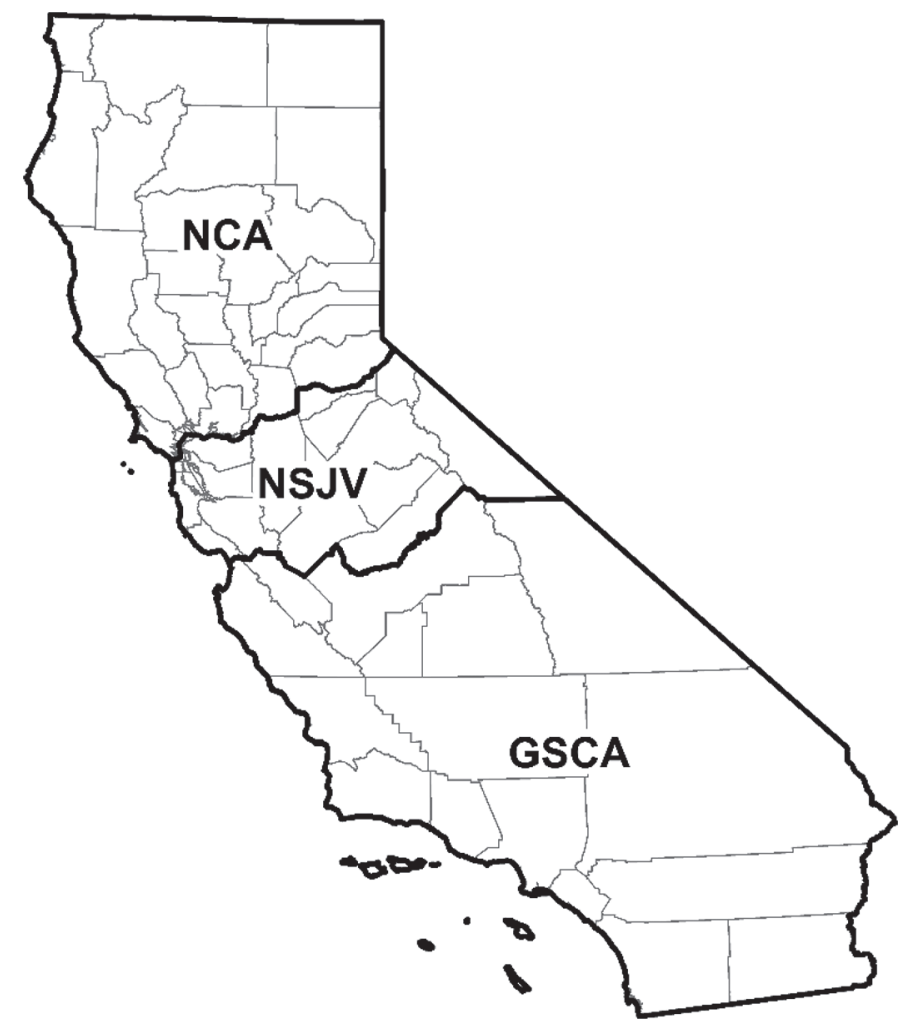

Figure 1. Map of counties in Northern California (NCA), northern San Joaquin Valley (NSJV), and greater Southern California (GSCA) used for comparison of survey responses. 


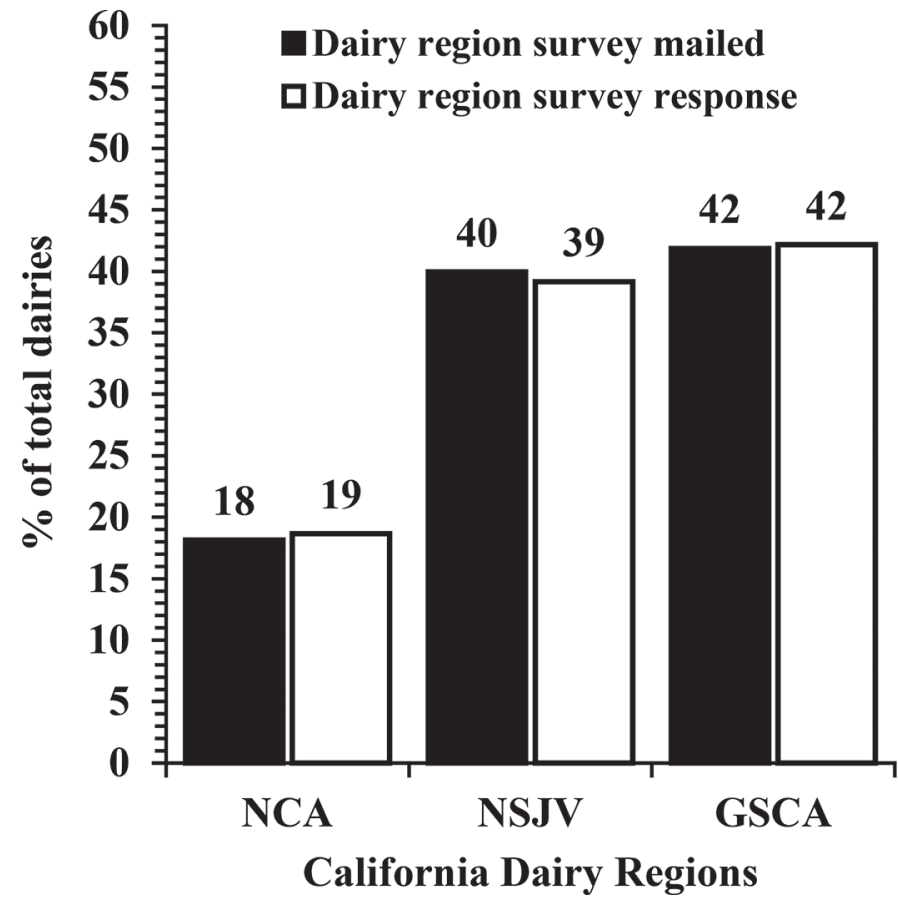

Figure 2. Distribution of surveys mailed $(\mathrm{n}=1,086)$ and surveys returned $(\mathrm{n}=166)$, by California dairy regions Northern California (NCA), northern San Joaquin Valley (NSJV), and greater Southern California (GSCA)

respondent dairies were in the $\mathrm{NCA}$ region than in the NSJV and GSCA regions. Respondents in NCA had smaller average herd size (522 milking cows, $P<0.01)$ than those in NSJV (1,316 milking cows) or GSCA (1,854 milking cows) regions. Respondents in GSCA also had larger $(P=0.03)$ herds than those in NSJV. The average herd size within region was comparable to that indicated by CDFA statistics (CDFA, 2018b) for 2017 (NCA: 435 lactating cows/dairy, NSJV: 1,176 lactating cows/dairy, GSCA: 1,761 lactating cows/ dairy), indicating that our survey was representative of the needs of dairy producers in different regions of the state.

Percentage of dairies that reported veterinarian visits weekly, biweekly, monthly, and not regularly was $29.5,42.2,14.5$, and $12.1 \%$, respectively. One respondent indicated that an on-farm veterinarian was used $(0.6 \%)$, and 2 respondents did not answer the question $(1.2 \%)$. Veterinary service visits were more frequent as herd size increased (Figure 3). A previous study also indicated that the frequency of veterinary service visits was significantly associated with herd size and with dairy production type (Richert et al., 2013). A great proportion of respondents (87\%) used a consultant to balance rations. Most respondents who did not use consultants to balance rations had $\leq 500$ milking cows, demonstrating that herd size may also influence the use of a consulting nutritionist. Veterinarians and dairy nutrition consultants are great assets for extension advisors and specialists to disseminate information. These professionals likely have greater contact with and linkage to their clients, because they frequently make farm visits. Dairy extension programs across the United States have been experiencing problems getting producers to participate in extension meetings (Hutjens and Baltz, 2000; Russell and Bewley, 2011). Focusing on different groups of clientele such as veterinarians and nutritionists may be another potential way to disseminate unbiased research-based information. Previous extension education programs such as the "Bovine Reproductive Ultrasound Workshop" (Fricke, 2002) have already demonstrated that veterinarians may be a great source when implementing new technology in the dairy industry. This program was implemented in Wisconsin in 1999 to train bovine practitioners in the use of ultrasound for dairy cattle reproductive management applications (Fricke, 2002). Creating "train the trainer" programs focusing on veterinarians and nutritionists may be an effective strategy to increase the reach of extension education programs and disseminate science-based information to dairy producers (Hutjens and Baltz, 2000; Mirando et al., 2012).

\section{Concerns or Obstacles Ranked by California Dairy Producers}

Survey respondents were asked to identify concerns or obstacles faced by California dairy producers from a list, including societal issues such as labor availability/quality and consumer demands. The 5 concerns or obstacles with the highest mean response indicated by respondents were (1) milk price, (2) labor availability/ quality, (3) environmental issues/regulations, (4) labor costs, and (5) water quality/availability (Figure 4 and Table 1). During the last $4 \mathrm{yr}$, lower milk prices have been the greatest challenge for dairy producers. Dairy extension programs that help producers reduce production costs while maintaining milk production per cow will have a significant impact on dairies during periods of low cash flow. Labor availability/quality appears to be a major management problem in the US dairy industry. As dairy size increases, dairy producers depend more on nonfamily labor. The labor-intensive dairy operational structure appears to make dairy jobs less desirable, and dairy farmers have had difficulty finding American workers to fill jobs on dairies (Harrison et al., 2009). The US dairy industry depends greatly on immigrant labor, which was estimated to account for $51 \%$ of total dairy labor (von Keyserlingk et al., 2013; Adcock 
et al., 2015). The majority of these immigrants are of Hispanic origin (Schenker and Gunderson, 2013). Dairy labor supply, including migrant labor, has reduced significantly in the last years. According to US Census Bureau data, the average number of annual new arrivals from Latin America and Mexico decreased 43 and $62 \%$, respectively, from 2010 to 2014 compared with 2000 to 2009 (Camarota and Zeigler, 2016). Because of changes in immigration policies, job opportunities in other areas, and changes in generation desires, a greater dairy labor shortage is expected in the future. Thus, keeping high-quality employees is vital to dairy farms. As dairy labor supply becomes more limiting and employees' technical skills become more required, the cost of turnover is higher (Hancock et al., 2013). A recent study indicated that dairy employee turnover rate is highly variable among dairy farms, ranging from 8 to $144 \%$ (Durst et al., 2018). Dairy farms that have less employee turnover will have to spend less time recruiting, selecting, hiring, and training new employees. As dairy herd size and technology use in dairy production increase, technical skills and quality of employees will be more indispensable for the financial health of the dairy business. Employee management varies widely among dairies and affects business performance and profitability (Estrada, 2017). Recent studies have indicated that dairy employee management assessment had several discrepancies when it was evaluated by the employer compared with by the employees (Erskine et al., 2015; Durst et al., 2018). Moreover, owners, managers, and employees identified dairy farm goals differently
(Durst et al., 2018). Thus, extension programs that include employee management and on-farm training and education of employees may benefit the dairy industry and should be evaluated (Erskine et al., 2015; Bernard, 2019).

In addition to labor availability and quality, labor cost was a top concern for California dairy producers. This result was most likely influenced by 2 California laws enacted in 2016 that will increase the hourly minimum wage from $\$ 10$ to $\$ 15$ by 2022 (State of California, 2016a) and require farmers to pay overtime for more than $40 \mathrm{~h} / \mathrm{wk}$ of work (State of California, 2016b). California dairy labor cost in 2016 was $\$ 1.74$ per hundredweight (cwt.) of milk, representing 10.5\% of milk production costs (CDFA, 2018a). The labor cost in 2017 ( $\$ 1.87 /$ cwt., representing $11.6 \%$ of milk production costs) increased by $7.5 \%$ compared with 2016 (CDFA, 2018a). During recent years, dairy producers have experienced hard times because of low commodity milk prices; any small increase in the cost of milk production can have a negative impact on the financial sustainability of a dairy business.

California dairy producers indicated great concern around environmental issues and regulations. California had several legislative changes related to environmental regulation of dairies in recent years. As dairy herds increase in size, social, animal, and environmental protection movements intensify their criticism of the dairy industry and raise the attention of the popular press. In 2016, California Senate Bill 1383 (State of California, 2016c) was approved with the objective of reducing

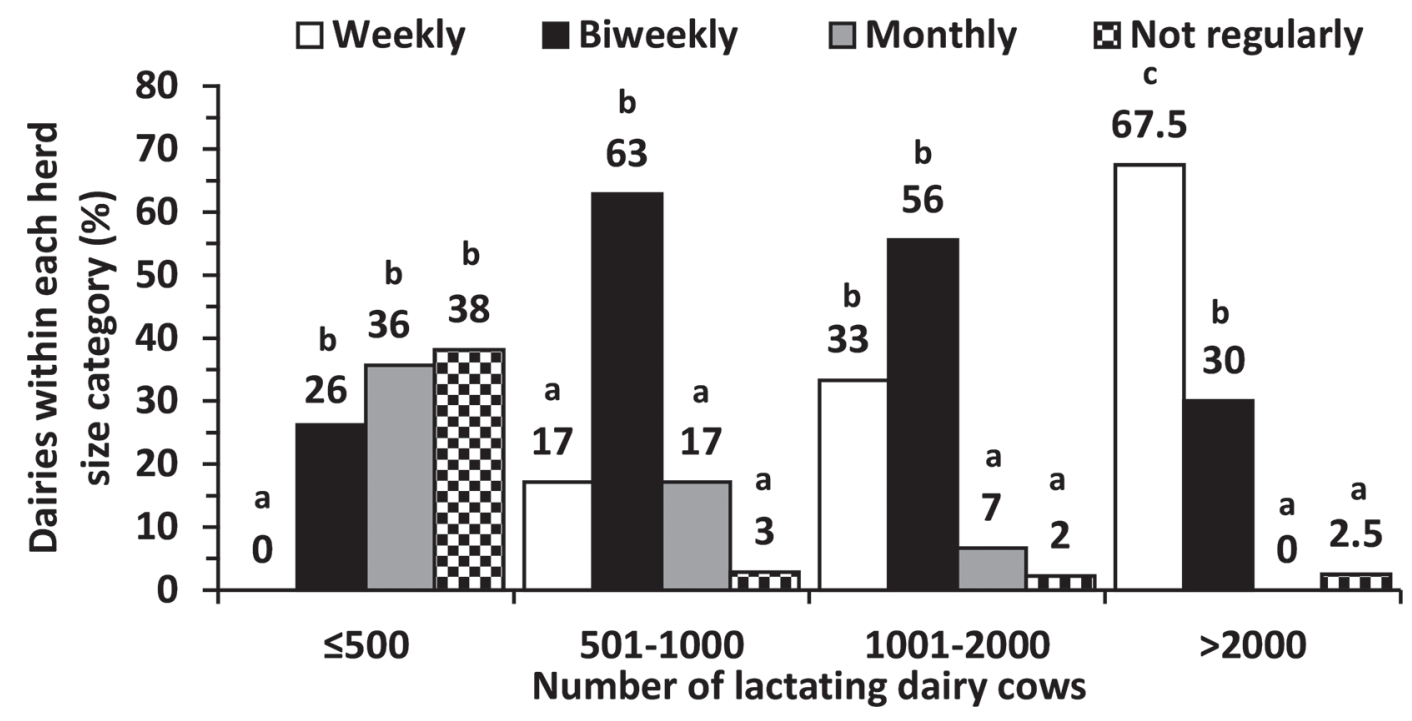

Figure 3. Distribution of dairies (\%) within each herd size category ( $\leq 500,501$ to 1,000, 1,001 to 2,000, and $>2,000$ lactating dairy cows) receiving veterinary service visits: weekly, biweekly (every $2 \mathrm{wk})$, monthly, or not regularly $(\mathrm{n}=162)$. One respondent with herd size between 1,001 and 2,000 lactating dairy cows had an on-farm veterinarian. Different letters $(\mathrm{a}-\mathrm{c})$ within a herd size category represent differences $(P<0.05)$. 
Dairy Producers Concerns/Obstacles

Very concerned $\square$ Somewhat concerned $\square$ Not concerned $\square$ No response

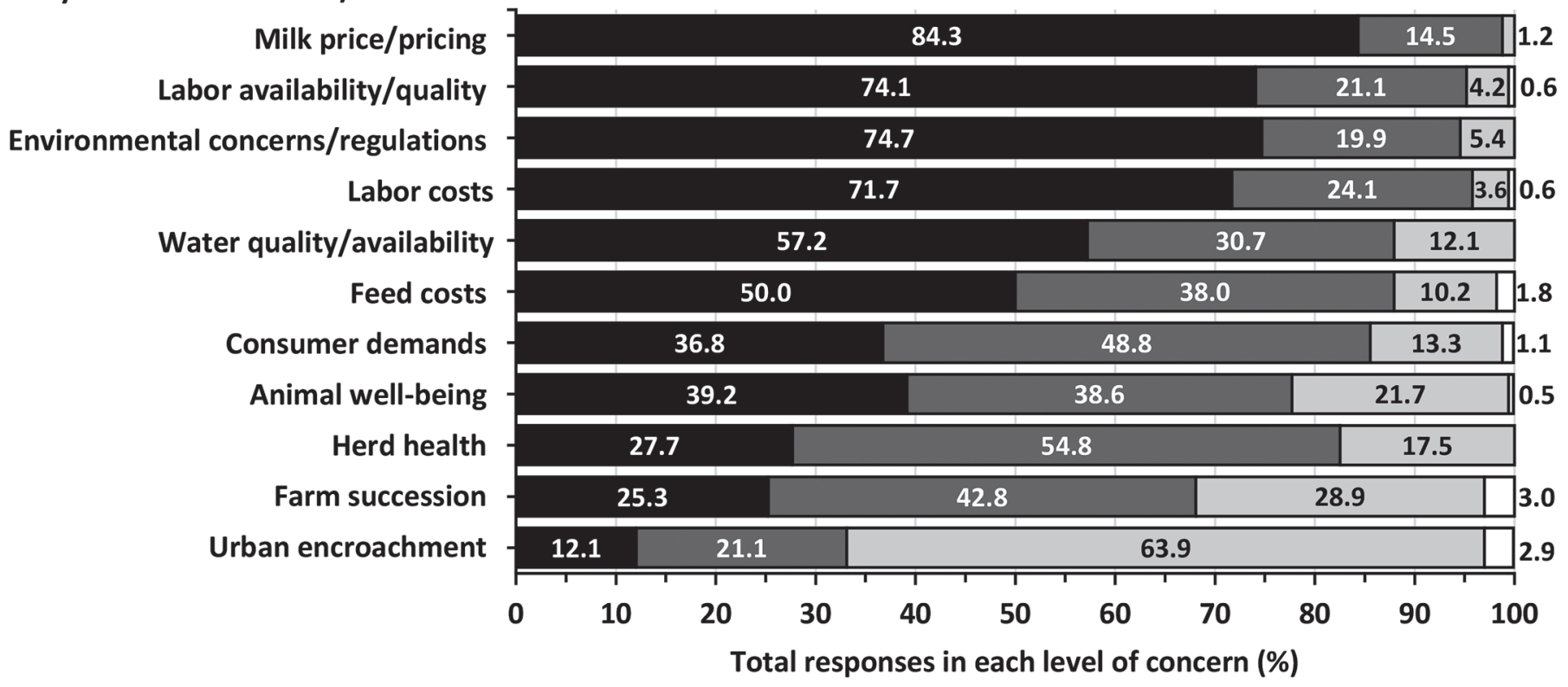

Figure 4. Percentage of total responses $(\mathrm{n}=166)$ in each rank of concern (very concerned, somewhat concerned, and not concerned) for concern/obstacle topics. Respondents who did not respond to a specific concern/obstacle were included as no response. Other written concerns/ obstacles included profitability, milk supply and demand (overproducing), and property taxes.

methane emissions from dairy manure management by 40\% (from 2013 levels) by 2030. Regulations to reduce dairy emissions cannot take effect until after January 1, 2024; however, dairy producers already showed a significant level of concern regarding potential new environmental regulations and the consequences to their business.

Water quality/availability was expected to be a top- 5 concern because California had the driest 4-yr period on record between 2011 and 2015. Most California dairies are located in the San Joaquin Valley, the region most affected by the drought (Wahl et al., 2017). The NSJV and GSCA regions had similar top-5 concerns/ obstacles but in different orders; however, the NCA region had feed cost and availability as a top-5 concern/ obstacle instead of water quality/availability. The lower concern with water quality/availability by producers located in the NCA region may be explained by the

Table 1. Level of concern $\left(\right.$ mean $\left.^{1} \pm \mathrm{SE}\right)$ for different topics categorized by region ${ }^{2}$ as indicated by respondents of the California dairy needs assessment survey

\begin{tabular}{|c|c|c|c|c|}
\hline Item & $\begin{array}{c}\text { Overall } \\
(\mathrm{n}=166)\end{array}$ & $\begin{array}{c}\text { NCA } \\
(\mathrm{n}=31)\end{array}$ & $\begin{array}{c}\text { NSJV } \\
(\mathrm{n}=65)\end{array}$ & $\begin{array}{c}\text { GSCA } \\
(\mathrm{n}=70)\end{array}$ \\
\hline 1. Milk price/pricing & $1.17 \pm 0.03^{\mathrm{a}}$ & $1.16 \pm 0.08^{\mathrm{a}}$ & $1.17 \pm 0.05^{\mathrm{a}}$ & $1.17 \pm 0.05^{\mathrm{a}}$ \\
\hline 2. Labor availability/quality & $1.30 \pm 0.04^{\mathrm{a}}$ & $1.26 \pm 0.10^{\mathrm{ab}}$ & $1.26 \pm 0.06^{\mathrm{abc}}$ & $1.35 \pm 0.07^{\mathrm{ab}}$ \\
\hline 4. Labor costs & $1.32 \pm 0.04^{\mathrm{a}}$ & $1.42 \pm 0.12^{\text {abc }}$ & $1.23 \pm 0.06^{\mathrm{ab}}$ & $1.35 \pm 0.06^{\mathrm{ab}}$ \\
\hline 5. Water quality/availability & $1.55 \pm 0.05^{\mathrm{b}}$ & $1.77 \pm 0.14^{\mathrm{bc}}$ & $1.58 \pm 0.08^{\mathrm{bcd}}$ & $1.41 \pm 0.08^{\mathrm{ab}}$ \\
\hline 6. Feed costs & $1.60 \pm 0.05^{\mathrm{b}}$ & $1.42 \pm 0.10^{\mathrm{abc}}$ & $1.60 \pm 0.09^{\mathrm{cd}}$ & $1.67 \pm 0.08^{\mathrm{bc}}$ \\
\hline 9. Herd health & $1.90 \pm 0.05^{\mathrm{cd}}$ & $1.90 \pm 0.13^{\mathrm{cd}}$ & $1.97 \pm 0.09^{\mathrm{e}}$ & $1.83 \pm 0.07^{\mathrm{c}}$ \\
\hline 10. Farm succession & $2.04 \pm 0.06^{\mathrm{d}}$ & $1.94 \pm 0.13^{\mathrm{cd}}$ & $1.94 \pm 0.09^{\mathrm{de}}$ & $2.18 \pm 0.09^{\mathrm{d}}$ \\
\hline 11. Urban encroachment & $2.53 \pm 0.06^{\mathrm{e}}$ & $2.42 \pm 0.14^{\mathrm{d}}$ & $2.55 \pm 0.09^{\mathrm{f}}$ & $2.57 \pm 0.08^{\mathrm{e}}$ \\
\hline
\end{tabular}

${ }_{\mathrm{a}-\mathrm{f}}$ Means within a column with different superscripts differ $(P<0.05)$.

${ }^{1}$ Mean response was calculated after assigning the following numeric values to producer concern level: very concerned $=1$, somewhat concerned $=2$, and not concerned $=3$.

${ }^{2} \mathrm{NCA}=$ Northern California, NSJV $=$ northern San Joaquin Valley, and GSCA $=$ greater Southern California. 
higher annual average precipitation and groundwater recovery compared with that in NSJV and GSCA.

\section{CE Research and Educational Priorities, Target Audience, and Methods of Delivery}

The 5 highest $\mathrm{CE}$ research priority topics indicated by dairy producers were (1) herd health issues, (2) environmental issues, (3) reproduction, (4) milk quality, and (5) water quality (Figure 5 and Table 2). The NSJV and GSCA regions had similar top-5 research priority topics, whereas the NCA region had calf and heifer management, manure management, and organic and pasture management as top-5 research priorities instead of reproduction, milk quality, and water quality. A recent survey indicated that a greater proportion of dairies in NCA raised their own preweaned calves on site compared with dairies located in NSJV and GSCA (100 vs. 44 and 50\%, respectively; Love et al., 2016). The addition of organic and pasture management as a top-5 research priority for the NCA region is because these systems are geographically concentrated in this region of the state and rarely found in the other regions of California (Love et al., 2016).

Dairy producers ranked (1) herd health issues, (2) milk quality, (3) reproduction, (4) environmental is- sues, and (5) calf and heifer management as the highest $\mathrm{CE}$ educational priority topics (Figure 6 and Table 3 ). All 3 regions had herd health issues, milk quality, and reproduction as top educational priorities. The NCA region included calf and heifer management and environmental issues as top-5 priorities, the NSJV region indicated environmental issues and manure management, and the GSCA region included water quality and heat stress. The NSJV and GSCA regions had more $\mathrm{CE}$ educational and research priority similarities than the NCA region, perhaps explained by differences in average dairy herd size, type of dairy production system (conventional, grazing, or organic), and climate of the NSJV and GSCA regions compared with the NCA region.

Herd health, reproduction, milk quality, and environmental issues were among the highest ranked research and educational opportunities identified by dairy producers. Although herd health ranked first for research and educational opportunities, it was ninth on the list of concerns. This result may be explained by the differences in topics between the 2 lists, with the concerns/obstacles list including societal issues that were not included as potential CE educational or research priorities. Kentucky dairy producers indicated that mastitis and milk quality were the most important

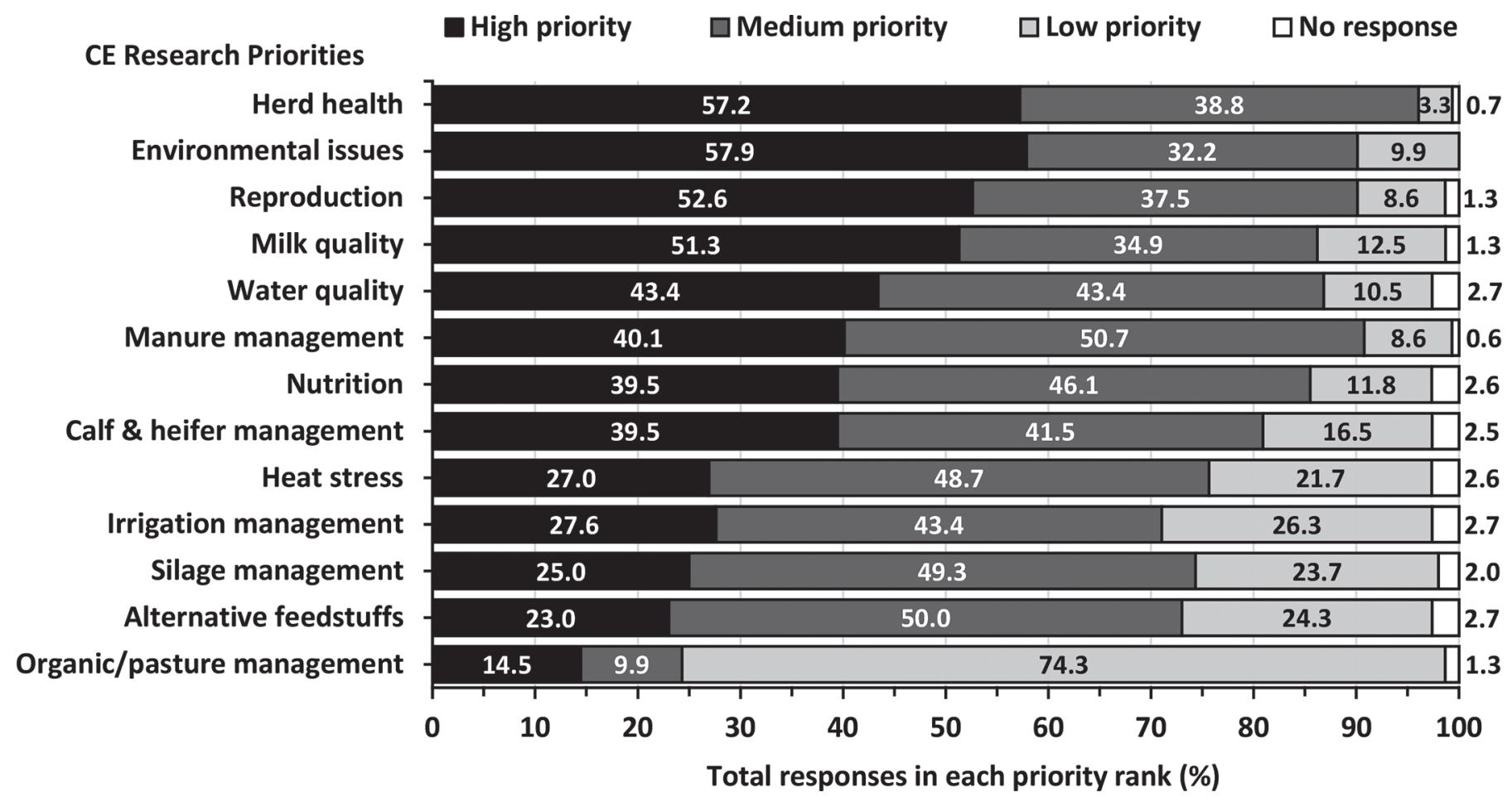

Figure 5. Percentage of total responses $(\mathrm{n}=152)$ in each rank of priority (high, medium and low) for cooperative extension $(\mathrm{CE})$ research priority topics. Respondents who did not respond to a specific research priority were included as no response. Other written $\mathrm{CE}$ research priority topics included medicine costs, water tables dropping, labor/automation, and milk health benefits. 
dairy management topic in extension programming among a list of 45 topics (Russell and Bewley, 2011). In the same survey, topics related to herd health such as disease prevention and vaccination, disease treatment, and lameness and hoof health were also top priorities (Russell and Bewley, 2011). Reproduction was also one of the most important topics, with $96 \%$ of respondents indicating it as an important or very important topic for dairy extension programming (Russell and Bewley, 2011). A previous survey performed in Canada also included udder health management and reproduction in the 3 highest priorities for both extension and research efforts indicated by producers. In 2017, reproduction, cow health, and milk quality were the 3 preferred topics for educational programs and the 3 management areas where Kansas dairy producers desired to make improvements (Voelz et al., 2017). Results of the current survey align with the results of these previous surveys, suggesting that herd health, reproduction, and milk quality topics are of great interest for research and education extension programs to dairy producers in different areas of the United States and Canada.

Dairy production has created significant environmental concerns. In the Kentucky survey, most producers $(90 \%)$ indicated that environmental issues were important or very important; however, it was only ranked the 25th most important of 45 topics (Russell and Bewley, 2011). Producers in California might have a greater interest in extension programs including environmental issues because of the great number of environmental regulations in California and its past impacts on California's dairy structure (Sneeringer and Hogle, 2008; Sneeringer, 2011).
Most respondents indicated that the target audience for the delivery of information should be dairy owners $(93 \%)$ or managers $(66 \%)$. Fewer producers indicated the target audience to be dairy employees $(27 \%)$ or allied industry (23\%). These results may be biased because the great majority of respondents $(88 \%)$ were dairy owners. Because producers had high concerns regarding labor quality and availability, we were expecting a greater percentage of producers to indicate that dairy employees were the target audience for extension programs. Producers seem reluctant to have their employees participating in extension educational programs. For instance, they may want to have greater control of employee educational program content and employee time spent on training. A recent study found that employers underestimated employees' interest in learning and overestimated employee perception of training frequency (Durst et al., 2018). Furthermore, dairy employees perceived that employers provided insufficient training. The study also identified several communication issues between dairy employers and employees (Durst et al., 2018). According to Erskine et al. (2015), the majority of employees (71\%) stated that they mainly received training on milking procedures by other employees or they learned by themselves. This previous study also found that immigrant employees were less likely to know farm goals and receive appropriate milking protocol training (Erskine et al., 2015). Therefore, it seems that the dairy industry has a great need for employee training programs.

Preferable information delivery methods were newsletter or magazine articles (81\%), half-day or short meetings (47\%), or on-farm training/meetings (39\%).

Table 2. Cooperative extension priority level $\left(\operatorname{mean}^{1} \pm \mathrm{SE}\right)$ for different research major topics categorized by region ${ }^{2}$ as indicated by respondents of the California dairy needs assessment survey

\begin{tabular}{|c|c|c|c|c|}
\hline Item & $\begin{array}{c}\text { Overall } \\
(\mathrm{n}=152)\end{array}$ & $\begin{array}{c}\text { NCA } \\
(\mathrm{n}=28)\end{array}$ & $\begin{array}{c}\text { NSJV } \\
(\mathrm{n}=61)\end{array}$ & $\begin{array}{c}\text { GSCA } \\
(\mathrm{n}=63)\end{array}$ \\
\hline 1. Herd health & $1.46 \pm 0.05^{\mathrm{a}}$ & $1.41 \pm 0.10^{\mathrm{a}}$ & $1.51 \pm 0.07^{\mathrm{a}}$ & $1.43 \pm 0.07^{\mathrm{a}}$ \\
\hline 2. Environmental issues & $1.52 \pm 0.05^{\mathrm{ab}}$ & $1.50 \pm 0.13^{\mathrm{a}}$ & $1.48 \pm 0.09^{\mathrm{a}}$ & $1.57 \pm 0.08^{\mathrm{abc}}$ \\
\hline 4. Milk quality & $1.61 \pm 0.06^{\mathrm{ab}}$ & $1.74 \pm 0.15^{\mathrm{a}-\mathrm{d}}$ & $1.61 \pm 0.09^{\mathrm{ab}}$ & $1.55 \pm 0.09^{\mathrm{ab}}$ \\
\hline 5. Water quality & $1.66 \pm 0.05^{\mathrm{ab}}$ & $1.70 \pm 0.14^{\mathrm{a}-\mathrm{d}}$ & $1.70 \pm 0.09^{\mathrm{ab}}$ & $1.60 \pm 0.08^{\mathrm{abc}}$ \\
\hline 6. Manure management & $1.68 \pm 0.05^{\mathrm{ab}}$ & $1.57 \pm 0.11^{\mathrm{ab}}$ & $1.74 \pm 0.08^{\mathrm{ab}}$ & $1.68 \pm 0.08^{\mathrm{abc}}$ \\
\hline 10. Irrigation management & $1.99 \pm 0.06^{\mathrm{d}}$ & $2.33 \pm 0.14^{\mathrm{de}}$ & $2.00 \pm 0.10^{\mathrm{b}}$ & $1.82 \pm 0.09^{\mathrm{bc}}$ \\
\hline 11. Silage management & $1.99 \pm 0.06^{\mathrm{d}}$ & $2.26 \pm 0.16^{\text {cde }}$ & $1.92 \pm 0.09^{\mathrm{b}}$ & $1.93 \pm 0.08^{\mathrm{c}}$ \\
\hline 12. Alternative feedstuffs & $2.01 \pm 0.06^{\mathrm{d}}$ & $2.19 \pm 0.12^{\mathrm{b}-\mathrm{e}}$ & $2.00 \pm 0.09^{\mathrm{b}}$ & $1.95 \pm 0.09^{c}$ \\
\hline 13. Organic/pasture management & $2.61 \pm 0.06^{\mathrm{e}}$ & $1.64 \pm 0.17^{\mathrm{abc}}$ & $2.80 \pm 0.06^{\mathrm{c}}$ & $2.85 \pm 0.06^{\mathrm{d}}$ \\
\hline
\end{tabular}

${ }^{\mathrm{a}-\mathrm{e}}$ Means within a column with different superscripts differ $(P<0.05)$.

${ }^{1}$ Mean response was calculated after assigning the following numeric values to producer response priority level categories: high priority $=1$, medium priority $=2$, or low priority $=3$.

${ }^{2} \mathrm{NCA}=$ Northern California, NSJV $=$ northern San Joaquin Valley, and GSCA $=$ greater Southern California. 
Table 3. Cooperative extension priority level $\left(\right.$ mean $\left.^{1} \pm \mathrm{SE}\right)$ for different extension major topics categorized by region ${ }^{2}$ as indicated by respondents of the California dairy needs assessment survey

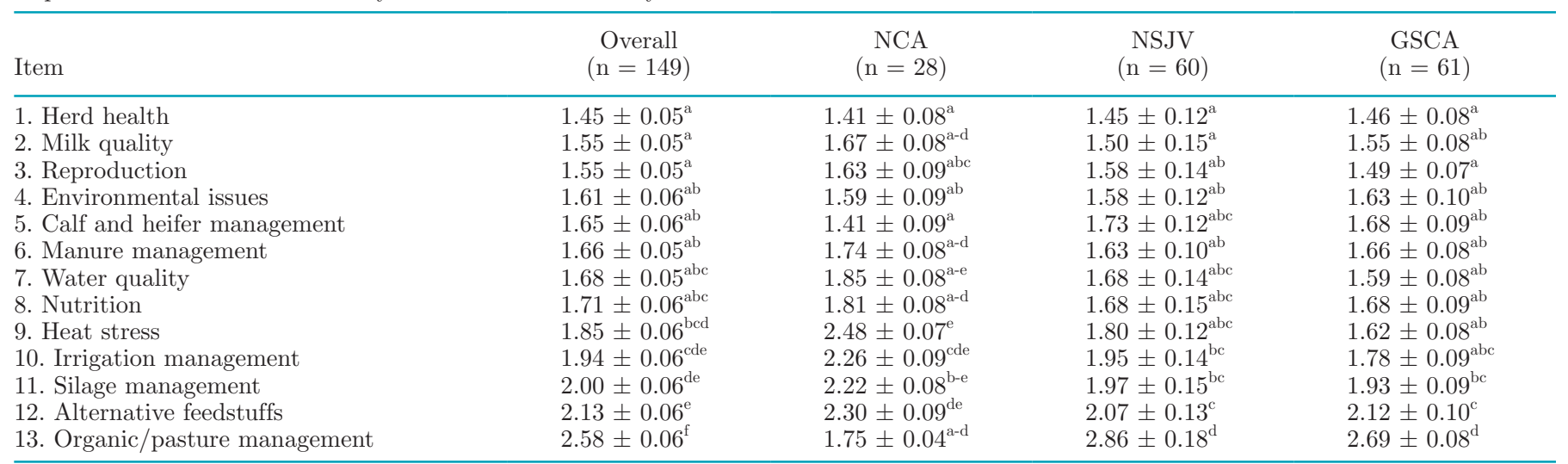

${ }^{\mathrm{a}-\mathrm{f}}$ Means within a column with different superscripts differ $(P<0.05)$.

${ }^{1}$ Mean response was calculated after assigning the following numeric values to producer response priority level categories: high priority $=1$, medium priority $=2$, or low priority $=3$.

${ }^{2} \mathrm{NCA}=$ Northern California, NSJV $=$ northern San Joaquin Valley, and GSCA $=$ greater Southern California.

Webinars and 2- or 3-d destination meetings were the least preferable methods (27 and 9\%, respectively). A previous survey conducted in Kentucky in 2008 also indicated a lower desire $(2.7 \%)$ for webinars as an information delivery method (Russell and Bewley, 2011). Today, most dairy producers have an internet connection and a smartphone. We expected a greater percentage of dairy producers to indicate webinars as a preferable information delivery method compared with more traditional extension methods. However, it appears that traditional information delivery methods such as newsletter or magazine articles should still be

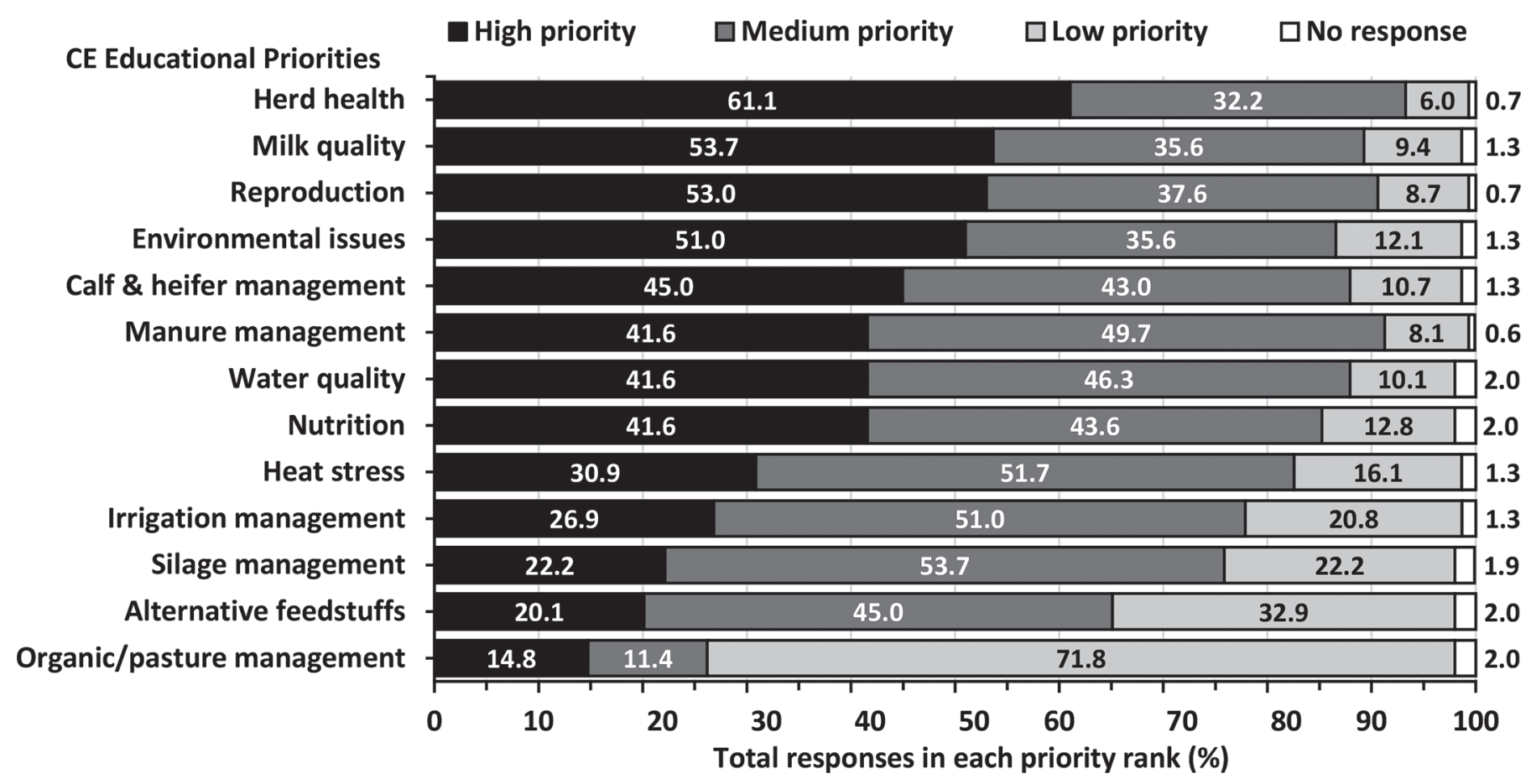

Figure 6. Percentage of total responses $(\mathrm{n}=149)$ in each rank of priority (high, medium, and low) for cooperative extension $(\mathrm{CE})$ educational priority topics. Respondents who did not respond to a specific educational priority were included as no response. Other written CE educational priority topics included pack barns, composting, labor/automation, and milk health benefits. 
used for extension programs to target dairy producers. The use of other tools such as social and digital media (e.g., YouTube, Facebook, and Instagram) should be investigated as information delivery methods for extension programs in the future, as suggested by Mirando et al. (2012). English and Spanish were the most desirable language options to deliver information to dairy employees, indicating that most respondents use Hispanic labor. Newsletters and on-farm training were the preferable information delivery methods for dairy employees.

\section{CONCLUSIONS}

This study provides valuable information for extension professionals, consultants, and allied industry to develop future research, extension, and outreach programs. Identifying priority areas may increase extension professionals' ability to serve their clientele by focusing on the high-priority issues. Herd size, production system type, and other local particularities should also be considered before determining extension program priorities. However, independent of location, dairy producers indicated that milk prices, environmental issues, and availability, quality, and cost of labor were their greatest concerns. Producers in all California regions determined herd health and environmental issues to be top priorities for research and extension programs. The results of this study will serve to develop future $\mathrm{CE}$ dairy programs in California that will prioritize the most important topics identified in this survey and information delivery methods desired by producers located in different regions of California. Other states that have similar dairy production systems may use this information to develop CE programs. Producers in these other states may be facing similar issues that affect California dairy producers.

\section{ACKNOWLEDGMENTS}

We gratefully acknowledge the participation of dairy producers in California. A special thanks to Walter Martinez (UCCE-Tulare) for assisting with survey data entry and Edna Blackhurst (UCCE-Tulare) for coordinating survey mailing.

\section{REFERENCES}

Adcock, F., D. Anderson, and P. Rosson. 2015. The economic impacts of immigration on U.S. dairy farms. Center for North American Studies, Texas A\&M University, College Station, TX. Accessed Sep. 23, 2018. http://www.nmpf.org/files/immigration-survey -090915.pdf.

Bernard, J. K. 2019. Invited review: Dairy extension programs in the southern region: Finding novel ways to meet the needs of our producers. Appl. Anim. Sci. 35:1-7.
Camarota, S. A., and K. Zeigler. 2016. Immigrants in the United States: A profile of the foreign-born using 2014 and 2015 Census Bureau data. Accessed Apr. 10, 2018. https://cis.org/sites/cis .org/files/immigrant-profile_0.pdf.

CDFA (California Department of Food and Agriculture). 2003. California dairy statistics and trends 2002. Accessed Sep. 23, 2018. https://www.cdfa.ca.gov/dairy/pdf/annual/2002/stats2002annual .pdf.

CDFA (California Department of Food and Agriculture). 2018a. California cost of milk production 2017 Annual. Accessed Jan. 23, 2018. https://www.cdfa.ca.gov/dairy/pdf/Annual/2017/COP _Annual2017Data.pdf.

CDFA (California Department of Food and Agriculture). 2018b. California dairy statistics annual 2017 Data. Accessed Sept. 23, 2018. https://www.cdfa.ca.gov/dairy/pdf/Annual/2017/2017_Statistics _Annual.pdf.

Chase, L. E., L. O. Ely, and M. F. Hutjens. 2006. Major advances in extension education programs in dairy production. J. Dairy Sci. $89: 1147-1154$

Custom Insight Inc. 2010. Survey random sample calculator. Accessed Sept. 23, 2018. https://www.custominsight.com/articles/random -sample-calculator.asp.

Durst, P. T., S. J. Moore, C. Ritter, and H. W. Barkema. 2018. Evaluation by employees of employee management on large US dairy farms. J. Dairy Sci. 101:7450-7462.

Erskine, R. J., R. O. Martinez, and G. A. Contreras. 2015. Cultural lag: A new challenge for mastitis control on dairy farms in the United States. J. Dairy Sci. 98:8240-8244.

Estrada, J. 2017. Setting goals and using performance feedback effectively. Pages 1221-1229 in Large Dairy Herd Management. 3rd ed. D. K. Beede, ed. Am. Dairy Sci. Assoc., Champaign, IL.

Fricke, P. M. 2002. Scanning the future - Ultrasonography as a reproductive management tool for dairy cattle. J. Dairy Sci. 85:1918 1926.

Hancock, J. I., D. G. Allen, F. A. Bosco, K. R. McDaniel, and C. A. Pierce. 2013. Meta-analytic review of employee turnover as a predictor of firm performance. J. Manage. 39:573-603.

Harrison, J., S. Lloydand, and T. O'Kane. 2009. Overview of immigrant workers on Wisconsin dairy farms. Changing Hands: Hired Labor on Wisconsin Dairy Farms. Briefing no. 1. Program on Agricultural Technology Studies. University of Wisconsin-Madison.

Heguy, J. M., D. Meyer, and N. Silva-del-Río. 2016. A survey of silage management practices on California dairies. J. Dairy Sci. 99:16491654 .

Hutjens, M. F., and J. H. Baltz. 2000. Keeping extension programs current in order to meet the needs of a dynamic dairy industry. J. Dairy Sci. 83:1412-1417.

Love, W. J., T. W. Lehenbauer, B. M. Karle, L. E. Hulbert, R. J. Anderson, A. L. Van Eenennaam, T. B. Farver, and S. S. Aly. 2016. Survey of management practices related to bovine respiratory disease in preweaned calves on California dairies. J. Dairy Sci. 99:1483-1494.

Mirando, M. A., J. M. Bewley, J. Blue, D. M. Amaral-Phillips, V. A. Corriher, K. M. Whittet, N. Arthur, and D. J. Patterson. 2012. Extension Education Symposium: Reinventing extension as a resource - What does the future hold? J. Anim. Sci. 90:3677-3692.

Richert, R. M., K. M. Cicconi, M. J. Gamroth, Y. H. Schukken, K. E. Stiglbauer, and P. L. Ruegg. 2013. Management factors associated with veterinary usage by organic and conventional dairy farms. J. Am. Vet. Med. Assoc. 242:1732-1743.

Russell, R. A., and J. M. Bewley. 2011. Producer assessment of dairy extension programming in Kentucky. J. Dairy Sci. 94:2637-2647.

Schenker, M., and P. Gunderson. 2013. Occupational health in the dairy industry needs to focus on immigrant workers, the new normal. J. Agromedicine 18:184-186.

Sneeringer, S., and R. Hogle. 2008. Variation in environmental regulations in California and effects on dairy location. Agric. Resour. Econ. Rev. 37:133-146.

Sneeringer, S. E. 2011. Effects of environmental regulation and urban encroachment on California's dairy structure. J. Agric. Resour. Econ. 36:590-614. 
State of California. 2016a. Senate Bill No. 3: An act to amend Sections 245.5, 246, and 1182.12 of the Labor Code, relating to Labor. Chapter 4. California. Accessed Mar. 25, 2019. https:// leginfo.legislature.ca.gov/faces/billTextClient.xhtml?bill_id= 201520160 SB3.

State of California. 2016b. Assembly Bill No. 1066: An act to amend Section 554 of, and to add Chapter 6 (commencing with Section 857 ) to Part 2 of Division 2 of, the Labor Code, relating to employment. Chapter 313. California. Accessed Mar. 25, 2019. https: //leginfo.legislature.ca.gov/faces/billNavClient.xhtml?bill_id= 201520160 AB1066.

State of California. 2016c. Senate Bill No. 1383.An act to add Sections $39730.5,39730.6,39730.7$, and 39730.8 to the Health and Safety Code, and to add Chapter 13.1 (commencing with Section 42652) to Part 3 of Division 30 of the Public Resources Code, relating to methane emissions. Chapter 395. California. https:/ /leginfo.legislature.ca.gov/faces/billNavClient.xhtml?bill_id= 201520160 SB1383.

University of California Agricultural and Natural Resources. 2017. UC dairy needs assessment underway. California Dairy Newsletter, vol.
9, page 1. AccessedMay 2, 2019. https://ucanr.edu/sites/Dairy/ newsletters/California_Dairy_Newsletter68952.pdf.

USDA. 2018. Milk Production. USDA-National Agricultural Statistics Services, Agricultural Statistics Board. Accessed Jan. 21, 2018. https://downloads.usda.library.cornell.edu/usda-esmis/files / h989r321c/4m90dw738/rx913r04v/MilkProd-02-21-2018.pdf.

Voelz, B. E., C. E. Payne, L. Hulbert, J. S. Stevenson, M. Brouk, and L. G. Mendonca. 2017. Kansas Dairy Producers' Needs Survey: Reproductive management on Kansas dairy farms. J. Ext. 55:4RIB6.

von Keyserlingk, M. A. G., N. P. Martin, E. Kebreab, K. F. Knowlton, R. J. Grant, M. Stephenson, C. J. Sniffen, J. P. Harner, A. D. Wright, and S. I. Smith. 2013. Invited review: Sustainability of the US dairy industry. J. Dairy Sci. 96:5405-5425.

Wahl, E. R., H. F. Diaz, R. S. Vose, and W. S. Gross. 2017. Multicentury evaluation of recovery from strong precipitation deficits in California. J. Clim. 30:6053-6063. 